John P. Ebert Do, James D. Pearson MD, Simon Gelman MD PhD, Constance Harris LPN, Edwin L. Bradley PhD

\title{
Circulatory responses to laryngoscopy: the comparative effects of placebo, fentanyl and esmolol
}

The circulatory response to a 30-second laryngoscopy followed by orotracheal intubation was recorded in 60 patients of ASA physical status III or IV undergoing a variety of non-cardiac surgical procedures. Patients were randomly allocated to either the placebo, esmolol $\left(500 \mu \mathrm{g} \cdot \mathrm{kg}^{-1} \cdot \mathrm{min}^{-1} \times 6\right.$ minutes, followed by $300 \mathrm{\mu g} \cdot \mathrm{kg}^{-1} \cdot \mathrm{min}^{-1} \times 9$ minutes), or fentanyl $\left(0.8 \mu \mathrm{g} \cdot \mathrm{kg}^{-1} \cdot \mathrm{min}^{-1} \times 10\right.$ minutes $)$ group, and the observer was blinded to the infusion administered. Esmolol blunted the heart rate $(H R)$ response, while fentanyl decreased it below the baseline and maintained it there, in spite of laryngoscopy. Similarly, fentanyl decreased the systolic (SBP), mean (MBP) and diastolic blood pressures (DBP) significantly below the baseline, while these pressures were either retained at or elevated slightly above control in the esmolol group. In these doses, the HR response to laryngoscopy was more effectively blocked by fentanyl, while esmolol better retained perfusion pressure. There were no complications or ischaemic electrocardiographic changes in any patient.

\section{Key words}

ANALGESICS: fentanyl; ANAESTHETIC TECHNIQUES: laryngoscopy; BLOOD PRESSURE: hypertension, hypotension; HEART: arrhythmia, tachycardia; INTUBATION, TRACHEAL: complications; SYMPATHETIC NERVOUS SYSTEM, $\beta$-adrenergic antagonists: esmolol.

From the Department of Anesthesiology, University of Alabama at Birmingham, Birmingham, Alabama.

Address correspondence to: Dr. J. Ebert, Department of Anesthesiology, University of Alabarna at Birmingham, 619 South 19th Street, Birmingham, Alabama 35233-1924.

Presented at the IARS 60th Congress, Las Vegas, Nevada, 1986.

Supported by a grant from DuPont Critical Care, Inc.
The potential for life-threatening complications associated with laryngoscopy and tracheal intubation in patients with coronary artery disease, ${ }^{1}$ systemic arterial hypertension, aneurysmal vascular disease, and decreased intracranial compliance ${ }^{2}$ is well known. The circulatory perturbations consist of elevations in heart rate (HR) and systemic $^{3,4}$ and pulmonary artery pressures, ${ }^{5}$ which occasicnally lead to myocardial ischaemia, ${ }^{6}$ heart failure and cerebrovascular catastrophies. ${ }^{7}$ These changes stem from reflex sympathetic discharge resulting from epipharyngeal and laryngo-pharyngeal stimulation, ${ }^{8}$ associated with increased plasma norepinephrine concentrations, ${ }^{9,10}$ and are marked by increased blood pressure (BP) and HR. The quest for effective blockade of these responses has included IV or topical lidocaine, ${ }^{3,11}$ vasodilators, ${ }^{12}$ adrenergic blockers, ${ }^{13}$ narcotics, ${ }^{14}$ and inhaled anaesthetics. ${ }^{15}$ In the appropriate dose, narcotics, like fentanyl, control both HR and BP responses; however, complex respiratory depression and truncal rigidity are frequent accompaniments. On the other hand, vasodilators and lidocaine provide an incomplete solution, controlling hypertension, but not affecting HR. Advocated by some, propranolol's effects outlasted the stressful interval by several hours, and not infrequently included increases in bronchomotor tone. Esmolol ${ }^{16}$ is an attractive option because of its beta, (cardioselective) adrenergic receptorblocking properties, and its short duration of action predicated on an elimination half-life of approximately nine minutes.

This study was designed to compare the circulatory effects of esmolol, fentanyl and placebo (control) on laryngoscopy and tracheal intubation in anaesthetized patients with severe systemic diseases (ASA physical status III and IV).

\section{Methods}

Following approval from the Institutional Review Board of the University of Alabama at Birmingham, written informed consent was obtained from each of 60 patients fulfilling the criteria for ASA physical status III or IV 

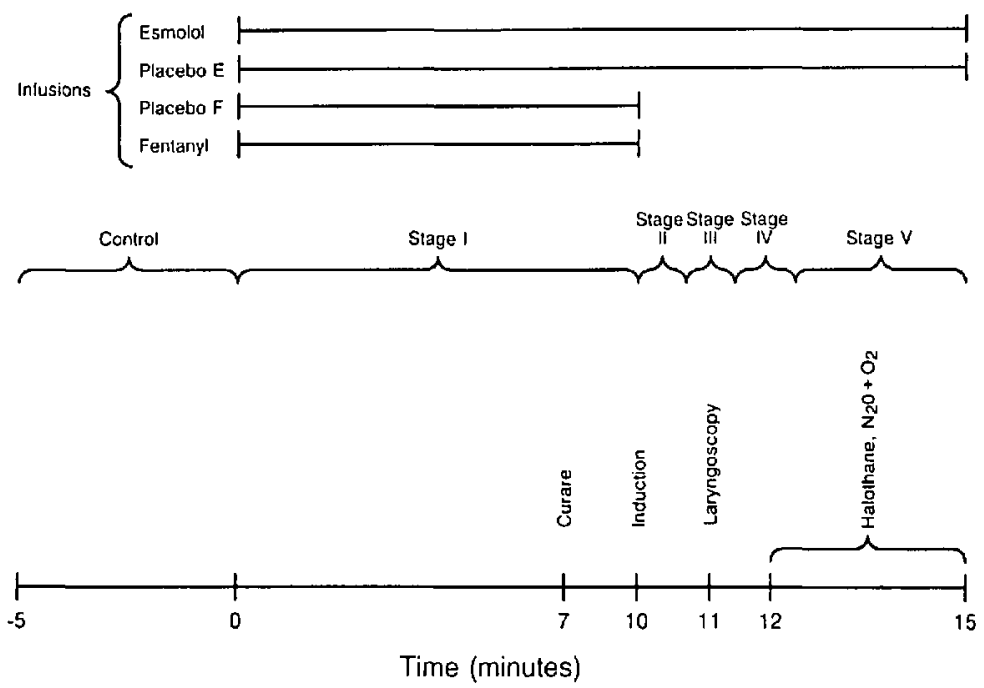

FIGURE 1 Study design.

scheduled to undergo a variety of non-cardiac surgical operations under general anaesthesia. Patients manifesting a life-threatening cardiac dysrhythmia, an acute myocardial infarction within three months of study entry, arterial hypotension less than $100 / 50 \mathrm{mmHg}$, or receiving beta-adrenergic or calcium-channel blockers within four elimination half-lives of study entry, or adrenergic augmenting or depleting drugs within six weeks of study entry were excluded from study. Patients were randomly assigned to one of three equal groups: placebo, esmolol or fentanyl. Each drug was packaged in a coded vial with the contents unknown to the observer, mixed in $100 \mathrm{ml}$ bags of five per cent dextrose and water, and was infused at a rate based on the patient's body weight using an IMED infusion pump. The code was not broken until the study was completed and the data analyzed. Ninety minutes following premedication with diazepam $10 \mathrm{mg} P O$, baseline variables were recorded for five minutes. Both ECG leads II and $V_{5}$ were observed and representative strip recordings obtained during critical intervals for analysis. Heart rate was recorded from $\mathrm{R}-\mathrm{R}$ intervals. When indicated for clinical reasons, systemic arterial pressure was determined, using a radial arterial cathetertransducer system, while in the remainder, noninyasive oscillometric measurements were obtained. If a monitored variable was observed more than once during a one-minute period, the highest observation for that period was the variable that was recorded for analysis. The study infusion was begun at time zero, d-tubocurarine $3 \mathrm{mg} \mathrm{IV}$ was administered at seven minutes, and anaesthesia was induced and muscle relaxation provided at ten minutes with thiopentone $3-5 \mathrm{mg} \cdot \mathrm{kg}^{-1}$ IV and succinylcholine $1.5 \mathrm{mg} \cdot \mathrm{kg}^{-1} \mathrm{NV}$, respectively. A 30 -second laryngoscopy was performed at 11 minutes. This 30 -second interval was measured with a stopwatch, commencing with exposure of the glottis and concluded with the intubation procedure. Anaesthesia was maintained with 60 per cent nitrous oxide in $\mathrm{O}_{2}$ and an inspired halothane concentration of 0-1.5 per cent determined on clinical grounds. The esmolol infusion was begun at time zero and continued until 15 minutes, infused at $500 \mu \mathrm{g} \cdot \mathrm{kg}^{-1} \cdot \mathrm{min}^{-1}$ for six minutes, and $300 \mu \mathrm{g} \cdot \mathrm{kg}^{-1} \cdot \mathrm{min}^{-1}$ for the next nine minutes. The fentanyl patients received an infusion of $0.8 \mu \mathrm{g} \cdot \mathrm{kg}^{-1} \cdot \mathrm{min}^{-1}$ started at time zero and completed at minute ten. In order to match the placebo patients to each of the two study groups, the placebo group was divided so that half of the patients received the placebo infusion for 15 minutes, and the other half for ten minutes. Variables (HR and BP) were recorded at one-minute intervals throughout the study period, which was divided into the control period, stage I (pre-induction), stage II (postinduction), stage III (laryngoscopy) and stage IV (postlaryngoscopy) (Figure I). The control, stage I and stage IV values represent the average of the one-minute 
TABLE I Distribution of physiological abnormalities contributing to patient classification as ASA physical status III or IV in 60 patients

\begin{tabular}{lccc}
\hline Physiological abnormality & $\begin{array}{c}\text { Placebo } \\
(n=20)\end{array}$ & $\begin{array}{c}\text { Esmolol } \\
(n=20)\end{array}$ & $\begin{array}{c}\text { Fentanyl } \\
(n=20)\end{array}$ \\
\hline Treated arterial hypertension & 9 & 9 & 10 \\
Ischaemic heart disease & 2 & 2 & 3 \\
- Previous myocardial infarct & 1 & 1 & 0 \\
- Stable angina pectoris & 2 & 2 & 3 \\
Abnormal preop ECG & 12 & 10 & 12 \\
- Supraventricular anthythmia & 2 & 1 & 0 \\
- Ventricular arrhythmia & 1 & 1 & 0 \\
- First degree A-V block & 1 & 4 & 2 \\
- Left bundle branch block & 6 & 2 & 4 \\
- Ischaemic S-T scgment & & & \\
$\quad$ abnomality & 1 & 3 & 3 \\
- Scar & 1 & 2 & 3 \\
Peripheral vascular disease & 1 & 2 & 0 \\
Chronic obstructive pulmonary & & & \\
$\quad$ disease & 9 & 8 & 9 \\
Cigarettes (pack-years) & $60 \pm 9.0$ & $42 \pm 5.4$ & $35 \pm 4.3$ \\
End-stage renal disease & 1 & 1 & 0 \\
Hepatic insufficiency & 0 & 0 & 1 \\
Diabetes mellitus & 3 & 2 & 5 \\
Collagen-vascular disease & 6 & 5 & 7 \\
Obesity* & 4 & 5 & 4 \\
\hline - & & &
\end{tabular}

*Excecds 120 per cent of ideal body weight for age and height.

determinations made during that stage. Data were statistically evaluated using one-way analysis of variance, with pair-wise comparisons between means made using the Fisher's protected least significant difference test. Errors in multiple comparisons were controlled by the use of the test. Differences were deemed significant at a $P$ value $<0.01$.

\section{Results}

Clinically evident increases in bronchomotor tone, greater than $1 \mathrm{~mm}$ ST segment change, or a noticeable increase in $P R$ interval did not occur in any patient. There were no significant differences among the groups in the distribution of physiologic abnormalities listed in Table $I$. Because there were no differences between any variables of the two placebo subgroups, data from these two subgroups were pooled, and will hereafter be referred to as the placebo group. Table II contains the measured haemodynamic values for all three groups.

These data indicate that laryngoscopy and subsequent intubation resulted in significant increases in HR and systolic (SBP), diastolic (DBP), mean blood pressure (MBP) and rate pressure product (RPP) in the placebo group. Infusion of esmolol caused an initial decrease in HR, modifying but not preventing the increases seen with induction of anaesthesia and laryngoscopy. While stage III (during laryngoscopy) HR changes in the esmolol group were not significantly different from those of the placebo group, the increase was blunted by esmolol: the mean $\mathrm{HR}$ value was $11 \mathrm{BPM}$ less than in the placebo group $(P<0.05)$. Esmolol had little effect on BP: the difference in mean values of SBP at stage III between esmolol and placebo groups (161 vs $183 \mathrm{mmHg}$ ) did not

TABLE II Haemodynamic data of 60 patients observed at six separate stages.

\begin{tabular}{|c|c|c|c|c|c|c|}
\hline & Control & Stage I & Stage II & Stage III & Stage IV & Stage V \\
\hline \multicolumn{7}{|c|}{ Esmolol group, $n=20$} \\
\hline HR (BPM) & $77.1 \pm 3.7$ & $69.2 \pm 2.9^{*}$ & $81.5 \pm 3.3 \dagger$ & $85.6 \pm 2.7 *, \dagger, \S$ & $80.2 \pm 2.7 \dagger$ & $76.0 \pm 2.6 \dagger, \|$ \\
\hline $\mathrm{SBP}(\mathrm{mmHg})$ & $152.5 \pm 4.9$ & $148.7 \pm 4.4$ & $145.7 \pm 7.0$ & $161.5 \pm 7.2 \ddagger .9$ & $161.2 \pm 5.9 \neq, 8$ & $138.9 \pm 4.99$ \\
\hline $\mathrm{DBP}(\mathrm{mmHg})$ & $78.6 \pm 3.1$ & $79.8 \pm 2.5$ & $95.8 \pm 5.1^{*}, \dagger, 8,1$ & $102.5 \pm 5.5 *, \dagger, 8,9$ & $99.4 \pm 4.31 *, \dagger, \$ .1$ & $83.4 \pm 3.69$ \\
\hline MBP (mmHg) & $105.7 \pm 3.4$ & $103.8 \pm 2.7$ & $112.4 \pm 5.39$ & $121.9 \pm 5.5^{*}, \dagger, \S, \eta$ & $118.4 \pm 4.91 *, \dagger, 8,1$ & $102.2 \pm 4.09$ \\
\hline \multicolumn{7}{|c|}{ Fentanyl group, $n=20$} \\
\hline HR (BPM) & $81.2 \pm 3.7$ & $78.4 \pm 3.9$ & $74.1 \pm 3.9 \|$ & $74.8 \pm 4.38 .1$ & $74.3 \pm 4.4$ & $65.4 \pm 3.9 *, f_{2} \|$ \\
\hline SBP (mmHg) & $164.4 \pm 8.3$ & $150.2 \pm 6.8$ & $122.9 \pm 9.6^{*}, \dagger$ & $124.1 \pm 8.4^{*}, \S, \|$ & $135.5 \pm 7.7^{*}, 5, \|$ & $108.5 \pm 6.3^{*}, \dagger, \|$ \\
\hline DBP (mmHg) & $86.1 \pm 3.5$ & $80.1 \pm 2.98$ & $67.4 \pm 4.6^{*}, \dagger, \|$ & $73.6 \pm 5.7^{*}, \|$ & $75.0 \pm 6.3 \|$ & $63.0 \pm 4.1^{*}, \|$ \\
\hline MBP (mmlig) & $112.1 \pm 4.5$ & $103.3 \pm 3.8 \S$ & $85.8 \pm 6.1^{*}, \dagger, \|$ & $90.6 \pm 6.3^{*}$, & $93.0 \pm 6.6^{*}, 5,4$ & $78.2 \pm 4.7 *$ \\
\hline \multicolumn{7}{|c|}{ Placebo group, $n=20$} \\
\hline HR (BPM) & $80.5 \pm 4.1$ & $78.6 \pm 3.8$ & $91.9 \pm 4.0^{*}, \dagger$ & $96.4 \pm 3.5^{*}, \dagger$ & $94.5 \pm 3.2 *, \dagger$ & $90.0 \pm 3.8^{*}, \dagger$ \\
\hline SBP (mmHg) & $145.3 \pm 6.9$ & $150.6 \pm 7.4$ & $154.9 \pm 9.7$ & $183.1 \pm 9.9^{*}, \dagger, \ddagger . \S$ & $186.6 \pm 9.6^{*}, \dagger, \ddagger . \S$ & $155.3 \pm 10.2$ \\
\hline $\mathrm{DBP}(\mathrm{mmH})$ & $76.8 \pm 4.3$ & $75.9 \pm 3.1$ & $89.4 \pm 4.5^{*}, f$ & $104.3 \pm 5.2^{*}, \dagger, \ddagger, 8$ & $99.4 \pm 4.9^{*}, \dagger, 8$ & $83.0 \pm 4.5$ \\
\hline MBP $(\mathrm{mmHg})$ & $98.3 \pm 4.7$ & $100.9 \pm 3.9$ & $111.2 \pm 5.7$ & $130.6 \pm 5.8^{*}, \dagger, \ddagger, \S$ & $128.3 \pm 5.8^{*}, \dagger, \ddagger, \S$ & $107.2 \pm 6.1$ \\
\hline
\end{tabular}

HR - heart rate, in beats per minute (BPM).

SBP - systolic blood pressure, in $\mathrm{mmHg}$.

DBP - diastolic blood pressure, in $\mathrm{mmHg}$.

$M B P$ - mean blood pressure, in $\mathrm{mmHg}^{\mathrm{H}}$.

$\checkmark$ alucs are expressed as mean $\pm S E M ; P<0.01$.

* vs control, same group. Tvs stage I, same group. ‡vs stage II, same group. §ీvs stage V, same group. fvs fentanyl, same stage. ||vs placebo, same stage 


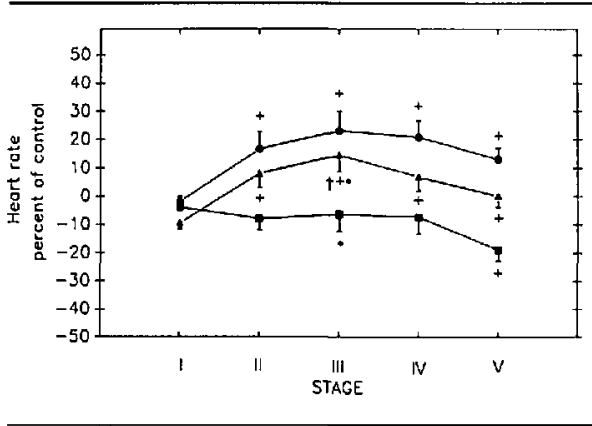

FIGURE 2 Per cent of control change in heart rate. Symbols: $\bullet=$ placebo, $\mathbf{A}=$ esmolol, $\mathbf{~ = ~ f e n t a n y l . ~ V a l u e s ~ a r e ~ e x p r e s s e d ~ a s ~}$ mean I SEM. ANOVA: + vs stage I, fvs stage II, †vs stage IV, * vs stage IV, $\mathrm{P}<0.01$.

reach statistical significance. The increase in the RPP was significantly less than that observed in the placebo group.

On the other hand, fentanyl administration induced significant decreases in HR, SBP, DBP, MBP, and RPP, and effectively blocked the responses to laryngoscopy and intubation. This degree of depression continued into the last stage and was significantly different compared with the other two groups at all stages except for stage I.

Figure 2 illustrates the changes in heart rate expressed as per cent of control for all three groups, while mean blood pressures (MBP) as per cent of control are presented in Figure 3. The first of these demontrates that fentanyl prevented, while esmolol only blunted, the HR changes associated with laryngoscopy. Figure 3 shows the MBP maintained slightly above control in the esmolol patients, and a decrease exceeding 20 per cent in the fentanyl group.

\section{Discussion}

It is a reasonable assumption that patients with infirmities warranting an ASA classification of $\mathrm{II}$ or IV are at greater risk for anaesthetic-related morbidity than their healthier counterparts. It follows then that at least some proportion of this group is in great need of protection from the stressful influences of laryngoscopy and intubation. For these reasons, we chose a study population which represented a cross-section of patients with important physiological compromises undergoing non-cardiac surgery. The technique of anaesthetic induction was selected because it was and still is clearly the most commonly employed method.

The esmolol infusion protocol employed in this study was chosen for several reasons. An earlier pilot study led

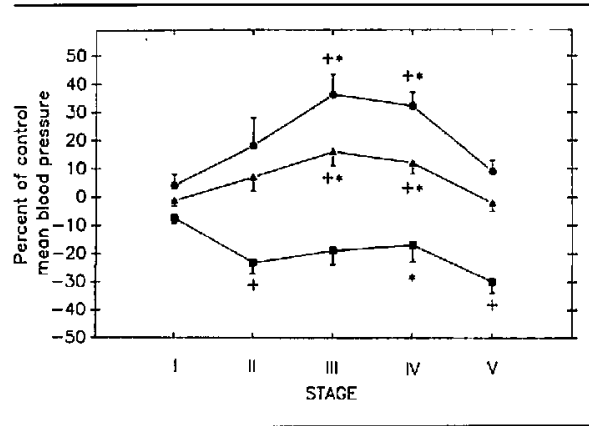

FIGURE 3 Per cent of control change in mean blood pressure. Symbols: $=$ placebo, $\boldsymbol{\Delta}=$ esmolol, $\boldsymbol{\square}=$ fentanyl. Values are expressed as mean \pm SEM. ANOVA: + vs stage I, †vs stage II, †vs stage IV, *vs stage IV, $P<0.01$.

to the identification of an infusion rate which would result in a plasma concentration associated with blunting of the cardiovascular responses to certain noxious stimuli without completely blocking the beta-adrenergic system. The infusion was continued beyond laryngoscopy in order to observe its effects in the presence of a commonly used anaesthetic with important cardio-circulatory depressant effects. Administration by infusion was necessitated by its short elimination half-life and duration of action. The dose of fentanyl was chosen because it had already been shown effective in blunting the circulatory response to tracheal intubation. ${ }^{14}$ Administration by infusion was required to maintain blinded, methodologic integrity.

Tachyarrhythmias observed during the induction of anaesthesia emanate from several sources. Preexisting fear and anxiety, with the attendant secretion of catecholamines contribute to some extent in every patient, while succinylcholine's effect on ganglionic transmission and predominant increased heart rate is well documented. ${ }^{17}$ The circulatory effects of laryngoscopy, both tachycardia and systemic hypertension, are proportional to the duration of conventional endoscopy, beginning at 15 and peaking at 45 seconds. ${ }^{18}$ The 30-second laryngoscopy followed by intubation was chosen so that protective measures could be adequately tested while not unduly endangering the patients in the placebo group.

The increase in HR exceeding the baseline by 20 per cent observed in the placebo group may be associated with critical increases in myocardial oxygen consumption. Despite this, ischaemic electrocardiographic changes did not occur, possibly because myocardial perfusion pres. sure was maintained.

Patients who received esmolol manifested circulatory 
changes that were not statistically different from the placebo group, but the HR and SBP responses to induction and endoscopy were certainly blunted. This clearly would have a beneficial effect on myocardial work, while the coexisting maintenance of DBP would facilitate perfusion. No attempt was made to assess the degree of $\beta$-adrenoceptor blockade ${ }^{19}$ associated with the dose of esmolol administered here, but the results indicate that the dose used did not provide a complete block, so one can speculate that a larger dose, or a shorter laryngoscopy for that matter, would have resulted in HRs closer to baseline values. Changes in RPP suggest that esmolol provided some measure of protection because the increase in RPP was less than half of that seen in the placebo patients ( 20 vs 50 per cent respectively).

Fentanyl, on the other hand, induced circulatory changes, which were not perturbed by laryngoscopy and intubation, but the $\mathrm{C}-\mathrm{V}$ function was further depressed as the anaesthetic proceeded. Unlike esmolol, fentanyl provides analgesia, but can also be accompanied by some potentially disturbing side effects, such as skeletal muscle ridigity (not seen in our patients) and the welldocumented postanaesthetic respiratory depression. ${ }^{20}$ Furthermore, fentanyl-induced decrease of DBP may detrimentally affect myocardial blood flow in some patients. This also was associated with a decrease in the RPP, but this study does not answer whether this decrease was protective or potentially harmful. It is clear that the SBP change made a larger contribution to this decrease than the HR (14 vs 6 per cent, respectively). The final answer to this question could only be found through the determination of oxygen regimen and metabolism within the myocardium, such as coronary sinus lactate concentration and oxygen tension. These drawbacks make esmolol attractive. It is conceivable, though not documented in our study, that a combination of a smaller dose of fentanyl with esmolol would provide a stable HR in the presence of modestly reduced or unchanged DBP, thereby optimizing the myocardial $\mathrm{O}_{2}$ supply-demand relationship.

Although infusion pumps were employed here, our subsequent experiences with esmolol have indicated that the drug can be safely administered as a bolus. Determination of bolus doses which would predictably block HR increases in those patients whose physiological compromises necessitate stability is a goal worthy of future study.

In the doses employed for patients of ASA physical status III or IV here, esmolol blunted but did not prevent heart rate changes of laryngoscopy while fentanyl did. Diastolic blood pressure, however, was better maintained in the esmolol patients. No patient manifested any ischaemic electrocardiographic changes.

\section{References}

1 Kaplan JA, King SB. The precordial electrocardiographic lead $\left(V_{5}\right)$ in patients who have coronary artery disease. Anesthesiology 1976; 45: 570-4.

2 Shapiro HM, Wyte SR, Harris AB, Galindo A. Acute intraoperative intracranial hypertension in neurosurgical patients: mechanical and pharmacologic factors. Anesthesiology 1972; 37: 399-405.

3 Stoelting RK. Blood pressure and heart rate changes during short-duration laryngoscopy for tracheal intubation: influence of viscous or intravenous lidocaine. Anesth Analg 1978; 57: 197-9.

4 Prys-Roberts C, Greene LT, Meloche R, Foëx $P$. Studies of anaesthesia in relation to hypertension. I: Haemodynamic consequences of induction and endotracheal intubation. Br J Anaesth 1971; 43: 531-46.

5 Sorenson $M B$, Jacobsen E. Pulmonary hemodynamics during induction of anesthesia. Anesthesiology 1977; 46: 246-51.

6 Roy $W L$, Edelist $G$, Gilbert $B$. Myocardial ischemia during non-cardiac surgical procedures in patients with coronary artery disease. Anesthesiology 1979; 51: 393-7.

7 Fox EJ, Sklar GS, Hill CH, Villanueva R, King BD. Complications related to the pressor response to endotracheal intubation. Anesthesiology 1977; 47: 524-5.

8 Tomori Z, Widdicombe JG. Muscular, bronchomotor and cardiovascular reflexes elicited by mechanical stimulation of the respiratory tract. J Physiol 1969; 200: 25-49.

9 Shepard LC, Gelman S, Reves JG, Oparil S. Humoral response of hypertensive patients to laryngoscopy. Anesth Analg 1981; 60: 276-7.

10 Menkhaus PG, Reves JG, Kissin I et al. Cardiovascular effects of esmolol in anesthetized humans. Anesth Analg 1985; 64: 327-34

11 Denlinger $J K$, Ellison N, Ominsky AJ. Effects of intratracheal lidocaine on circulatory responses to tracheal intubation. Anesthesiology 1974; 41: 409-12.

12 Stoelting RK. Attenuation of blood pressure response to laryngoscopy and tracheal intubation with sodium nitroprusside. Anesth Analg 1979; 58: 116-9.

13 Safwat AM, Reitan JA, Misle GR, Hurley EJ. Use of propranolol to control rate-pressure product during cardiac anesthesia. Anesth Analg 1981; 60: 732-5.

14 Martin DE, Ṙosenberg $H$, Aukburg SJ et al. Low-dose fentanyl blunts circulatory responses to tracheal intubation. Anesth Analg 1982; 61: 680-4.

15 Bedford RF, Marshall WK. Hemodynamic response to endotracheal intubation: four anesthetics. Anesthesiology 1981; 55: A270.

16 Gorczynski RJ, Shaffer JE, Lee RJ. Pharmacology of ASL-8052, a novel $\beta$-adrenergic receptor antagonist 
with an ultrashort duration of action. J Cardiovasc Pharmacol 1983; 5: 668-77.

17 Barreto RS. Effect of intravenously administered succinylcholine upon cardiac rate and rhythm. Anesthesiology 1960; $21: 401-4$.

18 Stoelting $R K$. Circulatory changes during direct laryngoscopy and tracheal intubation: influence of duration of laryngoscopy with or without prior lidocaine. Anesthesiology $1977 ; 47: 381-4$.

19 Dagnino J, Prys-Roberts $C$. Assessment of $\beta$ adrenoceptor blockade during anesthesia in humans: use of isoproterenol dose-response curves. Anesth Analg 1985; 64: 305-1.

20 Becker $L D$, Paulson BD, Miller RD, Severinghaus $J W$, Eger $E L$. Biphasic respiratory depression after fentanyl-droperidol or fentanyl alone used to supplement nitrous oxide anesthesia. Anesthesiology 1976; 44: 291-6.

\section{Résumé}

Nous avons mesuré la réponse hémodynamique à une laryngoscopie de 30 secondes suivie d' une intubation orotrachéale chez 60 patients de classe ASA III ou IV devant subir diverses interventions chirurgicales autres que cardiaques. Le hasard déterminait si la manoeuvre allait être précédée d'un placebo. d' esmolol $\left(500 \mu \mathrm{g} \cdot \mathrm{kg}^{-1} \cdot \mathrm{min}^{-1} \times 6\right.$ minutes, puis $300 \mu \mathrm{g} \cdot \mathrm{kg}^{-1}$. min $^{-1} \times 9$ minutes $)$, ou de fentanyl $\left(0.8 \mu \mathrm{g} \cdot \mathrm{kg}^{-1} \cdot \mathrm{min}^{-1} \times 10\right.$ minutes) et ce, dे l'insu d'un observateur neutre. L'esmolol limitait l' accélération du pouls tandis que le fentanyl ralentissait le coeur avant, pendant et apres la laryngoscopie. Avec le fentanyl, on a vu s'abaisser significativement les pressions artérielles systoliques, moyennes et diastoliques alors qu'elles se maintenaient ou s'élevaient légèrement avec l' esmolol. Ainsi, aux doses employées, le fentanyl prévient mieux la réponse chronotrope d la laryngoscopie alors que l' esmolol maintient la pression de perfusion. Nous n'avons noté aucune complication ni aucun signe électrocardiographique d' ischémie pendant cette étude. 